\title{
Anti-inflammatory Mechanisms Triggered by Apoptotic Cells during Their Clearance
}

\author{
Zsuzsa Szondy ${ }^{1,2 *}$, Zsolt Sarang ${ }^{1}$, Beáta Kiss ${ }^{1}$, Éva Garabuczi' and Krisztina Köröskényi1,2 \\ ${ }^{1}$ Department of Biochemistry and Molecular Biology of Medical Faculty, University of Debrecen, Debrecen, Hungary, \\ ${ }^{2}$ Department of Basic Medical Sciences of Dental Faculty, University of Debrecen, Debrecen, Hungary
}

OPEN ACCESS

Edited by:

Amiram Ariel,

University of Haifa, Israel

Reviewed by:

Sylvain Perruche,

Institut national de la santé

et de la recherche médicale, France

Patrizia Rovere Querini,

Vita-Salute San Raffaele

University, Italy

*Correspondence:

Zsuzsa Szondy

szondy@med.unideb.hu

Specialty section:

This article was submitted to

Molecular Innate Immunity,

a section of the journal

Frontiers in Immunology

Received: 12 May 2017

Accepted: 17 July 2017

Published: 02 August 2017

Citation:

Szondy Z, Sarang Z, Kiss B, Garabuczi É and Köröskényi K (2017)

Anti-inflammatory Mechanisms

Triggered by Apoptotic Cells

during Their Clearance.

Front. Immunol. 8:909.

doi: 10.3389/fimmu.2017.00909
In the human body, billions of cells die by apoptosis every day. The subsequent clearance of apoptotic cells by phagocytosis is normally efficient enough to prevent secondary necrosis and the consequent release of cell contents that would induce inflammation and trigger autoimmunity. In addition, apoptotic cells generally induce an anti-inflammatory response, thus removal of apoptotic cells is usually immunologically silent. Since the first discovery that uptake of apoptotic cells leads to transforming growth factor (TGF)- $\beta$ and interleukin (IL)-10 release by engulfing macrophages, numerous anti-inflammatory mechanisms triggered by apoptotic cells have been discovered, including release of antiinflammatory molecules from the apoptotic cells, triggering immediate anti-inflammatory signaling pathways by apoptotic cell surface molecules via phagocyte receptors, activating phagocyte nuclear receptors following uptake and inducing the production of anti-inflammatory soluble mediators by phagocytes that may act via paracrine or autocrine mechanisms to amplify and preserve the anti-inflammatory state. Here, we summarize our present knowledge about how these anti-inflammatory mechanisms operate during the clearance of apoptotic cells.

Keywords: apoptotic cell, phagocytosis, anti-inflammatory, pro-resolving lipid mediators, phosphatidylserine

\section{INTRODUCTION}

Timed initiation of apoptotic type of cell death followed by prompt removal carried out by professional engulfers or by non-professional neighboring cells plays a central role in the maintenance of tissue homeostasis. Every day billions of our cells die and get removed without inducing inflammation and autoimmunity (1). And even when inflammation is induced, efficient clearance of apoptotic neutrophils by engulfing macrophages during the inflammatory response is a determining event in initiating resolution of inflammation and contributes to the tissue repair processes following injury (2-5).

To initiate effective clearance, apoptotic cells attract engulfing cells by secreting various chemotactic signals, such as CX3CL1/fractalkine (6), lysophosphatidylcholine (7), sphingosine-1-phosphate (8), thrombospondin-1 (TSP-1) (9), ATP and UTP (10), endothelial monocyte-activating polypeptide II (11), monocyte chemoattractant protein-1 (12), cleaved human tyrosyl-tRNA synthetase (13), or the S19 ribosomal protein cross-linked dimer (14). Upon approaching the dying cells, engulfing cells must make a distinction between dead and living cells, and they act so by recognizing apoptotic cell-associated molecular patterns (ACAMPs) displayed on the cell surface of apoptotic cells (15). Most of the ACAMPs are phagocytosis initiating "eat me" signals, which are able to trigger receptors on phagocytes 
either directly or via bridging molecules. Phosphatidylserine (PS) on the outer leaflet of the cell membrane is the most universally seen "eat me" signal appearing in apoptotic cells (16). Stabilin-2, the macrophage receptor T-cell immunoglobulinand mucin-domain-containing molecule (Tim4), and brainspecific angiogenesis inhibitor 1 have the ability to directly engage PS on dying cells (17-19), other receptors, such as Mer tyrosine kinase (MerTk) (20), scavenger receptor SCARF1 (21), or integrin $\alpha \mathrm{v} / \beta 3 / \beta 5$ either with the CD36 (22) or with the transglutaminase 2 (TG2) coreceptors (23) require bridging molecules for PS binding. While for MerTk Gas6 and Protein S serve as bridging molecules $(24,25)$, TSP- 1 and milk-fat globulin-E8 play a similar role for the integrin $\alpha v / \beta 3 / \mathrm{CD} 36$ and integrin $\alpha \mathrm{v} / \beta 3 /$ TG2 receptor complexes, respectively $(22,26,27)$. In the case of apoptotic neutrophils, however, the matricellular protein CCN1 bridges PS to the $\alpha \mathrm{v} / \beta 3$ and $\alpha \mathrm{v} / \beta 5$ integrins of macrophages (28).

Besides the PS-recognizing bridging molecules, additional bridging molecules also contribute to the phagocytosis of apoptotic cells. Thus, serum protein C1q links Annexin A2 and A5 on the apoptotic cells (29) to both the SCARF1 scavenger receptor and to the calreticulin-associated CD91 receptor on macrophages $(20,30,31)$. Apoptotic neutrophils, T cells, and human mesangial cells release annexin I (32), and annexin I enhances phagocytosis of apoptotic cells via a mechanism that requires FPR2/ALX receptor and its internalization (33).

Interestingly, simultaneous triggering of all these phagocytic receptors seems to result in the activation of only two evolutionary conserved signaling pathways both leading to the activation of Rac1, a small GTPase that regulates cytoskeletal rearrangements required for the phagocytosis process (34).

Uptake of apoptotic cells delivers excess materials to the phagocytes, which is degraded after the newly formed phagosome fuses with the lysosomes $(35,36)$. However, for full protein degradation besides the lysosomal cathepsins (35), the proteosomal pathway also has to be activated (37). In addition, to successfully metabolize lipids originated from the apoptotic cells, phagocytes also require the lipid metabolism organizing function of their lipid sensing nuclear receptors, the liver X receptors (LXRs), and the perixosome proliferator-activated receptors (PPARs) (38). LXRs and PPARs are ligand-regulated transcription factors belonging to the nuclear receptor family. They function in the form of heterodimers with the retinoid X receptors (RXRs) (39). The unligated LXRs and PPARs are located on their respective DNA response elements and recruit co-repressor molecules that repress the transcription of their target genes. Binding of their ligand, however, induces such a conformational change in their structure that results in the exchange of co-repressors for co-activators, and in the consequent start of transcription. In addition, ligated LXR and PPAR heterodimers are also capable of transrepressing genes, the transcription of which would otherwise be initiated by other transcription factors (39).

The ligands of LXRs are sterol metabolites $(40,41)$, while for PPARs are unsaturated fatty acids, eicosanoids, and derivatives of linoleic acid (42). Metabolically, the main function of LXRs is to regulate whole body sterol metabolism (38). Since, in mammalians, sterols cannot be degraded; in macrophages, following the degradation of apoptotic cells, activated LXRs induce the expression of cholesterol efflux transporters ABCG1 and ABCA1, Apo lipoproteins ApoC and ApoE, and the lipoprotein remodeling enzyme PLTP (43) promoting this way the efflux of apoptotic cellderived sterols onto serum apolipoproteins and their transport to the liver, from where sterols will be redistributed again. PPARs, on the other hand, are involved in nearly every facet of fatty acid metabolism (44). Thus, PPAR $\gamma$ controls the expression of genes involved in lipid metabolism (43), while PPAR $\delta$ controls the macrophage energy homeostasis by regulating the expression of genes involved $\beta$-oxidation, mitochondrial respiration, and thermogenesis (45).

While engulfment of a number of pathogenic targets induces a pro-inflammatory program in macrophages, uptake of apoptotic cells initiates their transition into an anti-inflammatory phenotype. Furthermore, apoptotic cells are capable of actively inhibiting the inflammatory program. For example, the inflammatory response induced by lipopolysaccharide (LPS), a component of the cell wall of Gram-negative bacteria, is strongly attenuated by preincubation of macrophages with apoptotic cells (46-48). First, after the exposure to apoptotic cells, an immediate-early inhibition of macrophage pro-inflammatory cytokine gene transcription can be detected $(46,47)$, subsequently, both nuclear receptors (38) are activated and, as it was first recognized, soluble mediators, such as transforming growth factor (TGF)- $\beta$ and interleukin (IL)-10, are released (48). These mediators act via paracrine or autocrine mechanisms to strengthen and maintain the anti-inflammatory state $(47,48)$. The aim of this review is to highlight how these efferocytotic processes are coupled to the anti-inflammatory mechanisms provoked simultaneously by apoptotic cells, since efficient apoptotic cell removal and induction of immunologic tolerance by apoptotic cells are the two crucial mechanisms that prevent chronic inflammation and autoimmunity (49).

\section{APOPTOSIS IS AN IMMUNOLOGICALLY SILENT FORM OF CELL DEATH}

Increasing evidence indicates that the caspase-dependent apoptosis is unique in a sense that it is an immunologically silent form of cell death (50). Whereas necrotic cells typically provoke inflammation, apoptotic cells generally do not. What is more, even if apoptotic cells enter secondary necrosis and are leaking their cellular contents, they retain this anti-inflammatory state, in contrast to cells that have entered necrosis directly $(51,52)$. This suggests that significant alterations to cellular composition must occur during apoptosis to diminish the activity of dangerassociated molecules (DAMPs), and even if these are accidentally released, their pro-inflammatory activity is destroyed. There are several examples recently discovered that underline this assumption.

Genomic DNA is considered to be an important DAMP capable of initiating dendritic cell (DC) maturation and the initiation of immune responses to coadministered antigens (53). Conversely, hydrolysis of DNA with endonucleases strongly attenuates its immune-activating properties (54). In apoptotic cells, genomic DNA undergoes extensive hydrolysis to small $\sim 200 \mathrm{bp}$ fragments due to the actions of a caspase-activated DNAse (55). If DNA 
cannot be degraded by either apoptotic or phagocytic endonucleases, autoimmunity develops (55), which is related to incompletely digested DNA persisting in macrophages leading to the activation of the RIG-I/IRF-3 pathway which senses cytoplasmic DNA fragments (56). In addition to the caspase-dependent degradation of genomic DNA, activated caspase-8 itself also interferes with the RIG-I/IRF-3 pathway by proteolytically inactivating RIP kinase 1 , a key signaling component of the RIG-I complex, and thereby attenuating expression of IRF-3-inducible genes that include interferons and other inflammatory factors (57). Apoptotic caspases, via interfering with the cGAS/STING pathway, prevent the induction of type I interferons also by mitochondrial DNA, which can be released into the cytosol during apoptosis following permeabilization of the mitochondrial outer membrane (58).

High mobility group 1 (HMGB1) is another well-known DAMP. It functions in the cell nucleus as an architectural chromatin-binding factor via bending DNA and facilitating this way the buildup of protein complexes on specific DNA sequences. But it associates only loosely with the DNA, and can be passively released by necrotic or damaged cells (59). In apoptotic cells, however, HMGB1 remains bound firmly to chromatin due to the generalized hypoacetylation of histones, another caspase-dependent event (59). Furthermore, caspases also inactivate HMGB1 indirectly via cleaving the mitochondrial protein $\mathrm{p} 75 \mathrm{NDUF}$. This event triggers a burst of reactive oxygen leading to oxidation of a critical cysteine residue on HMGB1 that neutralizes its pro-inflammatory activity (60). And finally, IL-33, a recently discovered alarmin, is also cleaved by caspases loosing this way its DAMP activity (61).

\section{APOPTOTIC CELLS RELEASE ANTI- INFLAMMATORY MOLECULES}

Apoptotic cells not only fail to be strongly immunogenic but were found to release various anti-inflammatory molecules as well. Thus, T cells express TGF- $\beta$, and release it during apoptosis (62). TGF- $\beta$ is a potent anti-inflammatory cytokine (63). Its antiinflammatory effects are reflected in the observation that loss of TGF- $\beta 1$ in mice leads to wasting syndrome accompanied by a multifocal, mixed inflammatory cell response and tissue necrosis, resulting in organ failure and death $(64,65)$. Both the initiation and resolution of general inflammatory responses involve TGF- $\beta 1$. Thus, TGF- $\beta 1$ stimulates monocyte migration and growth factor production (66). But after initiation of an inflammatory response, it also exhibits potent anti-inflammatory effects, including inhibition of neutrophil and T-lymphocyte adhesion to endothelium (67), downregulation of macrophages $(66,68)$, and antagonism of tumor necrosis factor- $\alpha$ (TNF- $\alpha$ ) function (68). TGF- $\beta$ is crucial also in the initiation of differentiation of the regulatory $\mathrm{T}$ cells (69), which play a key role in preventing the development of autoimmunity (70). TGF- $\beta$ plays such an essential role in the initiation of regulatory $\mathrm{T}$ cell differentiation that prior to the initiation of thymocyte apoptosis no Treg cells can be detected in the thymus (71).

Apoptotic cells can also release IL-10 (72). IL-10, together with TGF- $\beta$, induces an immune suppressive response by promoting regulatory $\mathrm{T}$ cell formation and by affecting their function (73).
Annexin I, which is released by apoptotic cells and promotes efferocytosis $(32,33)$, was also found to significantly attenuate IL-6 signaling and the release of TNF- $\alpha$ from endotoxin-challenged monocytes by activating annexin A1 receptors of the formyl peptide receptor family and the consequent JAK/STAT/SOCS signaling (74). And, finally, apoptotic cells were found to release lactoferrin that inhibits the migration of neutrophil granulocytes and eosinophils toward the chemotactic signals released by apoptotic cells $(75,76)$. As a result, apoptotic cells induce only migration of macrophages, but other classes of professional phagocytes are not recruited by the apoptotic cells (76).

Increasing evidence indicate that several chemotactic signals released from the apoptotic cells can also serve as anti-inflammatory molecules. Thus, TSP-1 functions as a major activator of TGF- $\beta 1$ (77) which is secreted to the extracellular matrix in an inactive form by being in non-covalent association with the latency-associated peptide (78). First, TSP-1 releases TGF- $\beta 1$ from its latent form via interacting with the $\mathrm{N}$-terminal region of latency-associated peptide, then it binds the mature TGF- $\beta 1$. This interaction induces such a conformational change in the structure of TGF- $\beta 1$ (79), which allows its binding to its receptor. Furthermore, TSP-1 or its protease-cleaved derivative can also bind to immature DCs (iDCs) and induce their tolerogenic state (80). Fractalkine was also shown to act as an inhibitor of LPS-induced TNF- $\alpha$ production by microglia cells (81), while lysophosphatidylcholine was reported to interfere with the LPS-induced NO and pro-inflammatory cytokine production by macrophages (82).

Once released from the apoptotic cells via a caspase-regulated pannexin channel (83), ATP is fast degraded to AMP very often on the surface of apoptotic cells (84) and then to adenosine by the cell surface $5^{\prime}$ nucleotidase of engulfing macrophages $(85,86)$. Adenosine then triggers macrophage adenosine $\mathrm{A}_{2 \mathrm{~A}}$ receptors (A2ARs) to suppress the NO-dependent formation of neutrophil migration factors, such as macrophage inflammatory protein-2, via activating the adenylate cyclase/protein kinase A pathway (86). Interestingly, both adenosine $\mathrm{A}_{2 \mathrm{~A}}$ and $\mathrm{A}_{3}$ (A3R) receptors are expressed by macrophages, and while A2ARs inhibit, A3Rs promote the release of neutrophil migration factors by engulfing macrophages (87). However, while A2AR expression increases (86), A3R is downregulated during the course of efferocytosis (87) potentiating and maintaining this way the anti-inflammatory effects of adenosine. In addition, adenosine, by triggering adenosine $\mathrm{A} 3 \mathrm{R}$, contributes also to the chemotactic navigation of macrophages toward the apoptotic cells driven by apoptotic cell-derived chemotactic signals, thus facilitates the fast clearance of apoptotic cells (88). As a result, downregulation of A3R during clearance prolongs their presence around the apoptotic cells.

In an inflammatory milieu, adenosine strongly suppresses also the LPS-induced pro-inflammatory cytokine formation of monocytes and macrophages by activating A2ARs (89). In monocytes adenosine increases the expression of the $\mathrm{Nr} 4 \mathrm{~A}$ orphan nuclear receptor which then inhibits the transcriptional activity of nuclear factor- $\kappa \mathrm{B}(\mathrm{NF}-\kappa \mathrm{B})$ known to play a determining role in initiating the transcription of numerous pro-inflammatory cytokines (90). The adenosine-triggered adenylate cyclase pathway in LPS-activated macrophages, on the other hand, upregulates the 
expression of dual-specific phosphatase 1 that interferes with the activation of LPS-activated MAP kinases (91).

\section{APOPTOTIC CELLS TRIGGER ANTI- INFLAMMATORY SIGNALING PATHWAYS BY ACTIVATING CELL SURFACE PHAGOCYTOSIS RECEPTORS ON THE PHAGOCYTE}

Soon after it was discovered that PS recognition plays a central role in the uptake of apoptotic cells (92), it was also discovered that PS recognition in macrophages mediates also some of the anti-inflammatory responses observed during the uptake of apoptotic cells (93). This was proven by the observation that several anti-inflammatory responses provoked by apoptotic cells can be prevented by administration of annexin $\mathrm{V}$, a naturally occurring PS binding protein (92), or are not induced by cells that do not express PS during apoptosis. In addition, in the induction of these anti-inflammatory effects, apoptotic cells can be replaced by PS liposomes (94). Some of the PS-induced anti-inflammatory responses are direct and can be detected as immediate inhibition of NF- $\kappa B$ transcriptional activity (46). Some others appear later, such as upregulation of the zinc finger nuclear factor, named GC binding protein (GC-BP) (95), or that of the Nr4al transcription factor (96). By binding to its promoter, GC-BP selectively inhibits IL-12 p35 gene transcription (95), while Nr4alinhibits both NF- $\kappa$ B transcriptional activity and the induction of IL-12 (96). The induction of these transcription factors, however, might be macrophage type specific, because Nr4al induction is seen in peritoneal, but not in bone marrow-derived macrophages (96).

In addition to these intracellular anti-inflammatory effects, PS is also responsible for triggering TGF- $\beta 1$ secretion from engulfing macrophages. Thus, apoptotic PLB-985 cells that are unable to express PS during apoptosis, fail to trigger TGF- $\beta 1$ production, while PS directly transferred onto the PLB-985 cell surface membranes or PS liposomes can restore the secretion of TGF- $\beta 1$ (94).

Since PS is recognized by a number of phagocytic receptors and opsonins that span a wide range of gene families, it is very likely that they induce immune suppression and tolerance via overlapping and non-overlapping mechanisms. Among the PS receptors, TIM-4 is not expected to transmit anti-inflammatory signals; since in the absence of a cytoplasmic tail, it alone cannot activate an intracellular signaling pathway (97). However, stabilin- 2 was shown to be involved in inducing TGF- $\beta 1$ release from engulfing macrophages (18), while MerTk was found to have a direct anti-inflammatory activity that suppresses NF- $\mathrm{kB}$ (98). The anti-inflammatory action of MerTk is independent of its effect on efferocytosis and is related to a signal transduction pathway that prevents the LPS-induced phosphorylation of I $\mathrm{KB}$ kinase and the consequent degradation of I $\mathrm{BB}$ (98). Whether other phagocytosis receptors also participate in the induction of the anti-inflammatory response of macrophages is still under investigation, but CD36 and $\alpha_{v} \beta_{3}$ receptors do not seem to participate in it (99). Interestingly, however, loss of both MerTk and TG2 leads to pro-inflammatory cytokine production during efferocytosis $(100,101)$. But the pro-inflammatory cytokine production in this latter case might be related not only to an improper integrin signaling for which TG2 is a cofactor but also to the fact that TG2 is required for proper TGF- $\beta$ activation by macrophages (102).

Phosphatidylserine receptors are expressed not only by macrophages but by other immune cells as well. As a result, apoptotic cells can transmit further immune silencing signals via activating PS receptors on those cells as well. For example, it has been shown that in the presence of apoptotic cells, iDCs do not induce expression of DC maturation-markers, such as MHC class-II, CD40, CD80, CD83, and CD86, even after challenge with CD40-signaling, monocyte-conditioned medium, LPS, or TNF- $\alpha$ (103-108). Furthermore, activation of PS receptors in human DCs by PS liposomes reduces their IL-12p70 secretion and the capacity to stimulate allogeneic $\mathrm{T}$ cell proliferation and to activate IFN- $\gamma$-producing CD4 ${ }^{+}$T cells (109). iDCs express MerTK, and activation of MerTK in iDCs triggers the phosphatidylinositol 3-kinase signaling pathway, which inhibits NF- $\kappa \mathrm{B}$ activation and the consequent DC maturation (110). As a result, iDCs, which do not express MerTk or are treated with phosphatidylinositol 3-kinase inhibitors, do not respond to the immunosuppressing effect of apoptotic cells on LPS-induced pro-inflammatory cytokine formation (111). DCs also express Axl, another member of the TAM receptor family. The basal expression of Axl in DCs is very low, but it is significantly upregulated following TLR engagement. Axl, following activation, induces resolution of inflammation at the end of an inflammatory cycle (111). Ligation of the thrombospondin receptor CD36 also inhibits iDC maturation and function by suppressing the release of IL-12 and the secretion of high levels of IL-10 in response to DC-activation stimuli (105).

$\mathrm{T}$ cells, on the other hand, express the PS receptor TIM-3, another member of the TIM receptor family. In T cells, TIM-3, following PS exposure, transmits an immunosuppressive signal by sequestering lck, a critical tyrosine kinase participating in $\mathrm{T}$ cell receptor-mediated signal transduction (112).

In addition to PS, late apoptotic neutrophils were shown to express also pentraxin 3 (PTX3) in their membranes (113). PTX3 was shown not only to enhance their phagocytic removal during inflammation (113) but also to induce the expression of CD169 in macrophages (114), a molecule that interferes with the development of an autoimmune response (115).

\section{NUCLEAR RECEPTORS ACTIVELY SUPPRESS PRO-INFLAMMATORY CYTOKINE FORMATION BY INHIBITING NF-KB}

Once apoptotic cells are taken up, they have to be fast metabolized by macrophages in order to ingest further apoptotic cells. Uptake of high amount of extracellular material might induce a metabolic stress in the engulfing macrophages, and engulfing macrophages respond to it in many ways by altering their metabolism. Interestingly, these metabolic adaptors also seem to contribute to the immune silencing processes as well. Thus, the amino acid metabolic-stress sensing protein kinase GCN2 was implicated to participate in the signaling pathways that lead to tolerance (116). 
Similarly, the lipid sensing nuclear receptors that function during engulfment as transcriptional regulators of lipid metabolic processes also interfere with inflammatory processes, such as those initiated by TLR signaling in macrophages. As it was reviewed by Kidani et al. (38), under non-inflammatory conditions, NF- $\mathrm{KB}$ target genes are kept in an inhibited state by co-repressor complexes associated with their promoters. As a response to inflammatory signaling, proteins of these corepressor complexes become ubiquitinated and subsequently degraded by the $19 \mathrm{~S}$ proteasome. At the same time, NF- $\kappa \mathrm{B}$ activated simultaneously by the inflammatory signals translocates into the nucleus, binds to promoters of inflammatory genes, and induces their expression. Ligation of PPAR $\gamma$ during efferocytosis prevents NF- $\mathrm{BB}$-regulated gene expression by sustaining co-repressor binding on the promoters of NF- $\mathrm{KB}$ target genes. This is related to the fact that ligand binding to PPAR $\gamma$ induces conformational changes that allows for SUMOylation of its ligand-binding domain. SUMOylated PPAR $\gamma$, subsequently, binds to the co-repressor complex and prevents its degradation by the $19 \mathrm{~S}$ proteasome, thereby sustaining the suppressed state. LXR-mediated transrepression of NF- $\mathrm{KB}$ target genes operates via similar mechanisms involving SUMOylation of LXR by HDAC4, SUMO2, or SUMO3 as the E3-ligase (38).

Ligated PPAR $\delta$ also interferes with the NF- $\kappa$ B transcription, but it operates through a different mechanism. BCL-6 is an evolutionarily conserved zinc finger transcription factor that acts as a sequence-specific repressor of transcription. Unliganded PPAR $\delta$ sequestrates BCL- 6 away from the promoters of inflammatory genes; while following ligand binding PPAR $\delta$ releases BCL-6 leading to suppression of inflammatory gene transcription (117).

Ligated nuclear receptors are also anti-inflammatory because during efferocytosis they upregulate the expression of various phagocytic receptors, thus, enhance the clearance capacity of macrophages (118-122). The upregulation of some phagocytic genes by these receptors, such as MerTk by LXR, is direct, while that of others is mediated via retinoic acid receptor (RAR)- $\alpha$ (121, 122). In engulfing macrophages, activation of all lipid sensing receptors leads to the upregulation of retinaldehyde dehydrogenase expression, an enzyme responsible for retinoic acid synthesis (123). Retinoic acids, ligands for the RAR and RXR receptors, then can promote both the transcriptional activity of lipid sensing nuclear receptors and trigger that of the RARs (122). In addition, LXRs are also involved in the induction of the synthesis of polyunsaturated fatty acids, which are precursors for the production of pro-resolving lipid mediators (124). And finally, ligated nuclear receptors are also responsible for the upregulation of A2ARs that mediate the anti-inflammatory effect of adenosine (86).

Besides the lipid sensing nuclear receptors, the orphan nuclear receptor Nr4a1 has also been implicated to act as an anti-inflammatory molecule during efferocytosis (96). Nr4a1 seems to interfere with the TLR signaling pathway at two levels: (1) it can interact with TRAF6, a central adaptor molecule in the TLR signaling pathway. The interaction affects TRAF6 autoubiquitination leading to the suppression of NF- $\mathrm{KB}$ activation and to that of the subsequent transcription of pro-inflammatory cytokines (125). (2) It directly associates with the p65 subunit of $\mathrm{NF}-\kappa \mathrm{B}$ and prevents its binding to the $\kappa \mathrm{B}$ promoter. However, this latter effect of Nr4a1 might be suspended by its LPS-induced p38 $\alpha$ phosphorylation (126).

\section{MACROPHAGES RESPOND TO APOPTOTIC CELL UPTAKE BY RELEASING ANTI-INFLAMMATORY OR PRO-RESOLVING MOLECULES}

Since the first discovery that macrophages engulfing apoptotic cells release TGF- $\beta$ and IL-10 $(47,48)$, numerous other anti-inflammatory molecules have been described to be released by engulfing macrophages. Many of these anti-inflammatory molecules are lipid mediators, such as $\mathrm{PGE}_{2}, \mathrm{PGF}_{1 \alpha}, \mathrm{LXA}_{4}$, or PAF, the synthesis of which is interestingly dependent on TGF- $\beta$ (127). TGF- $\beta$ at the same time inhibits the synthesis of pro-inflammatory lipid mediators. While in the case of TGF- $\beta$, it was found that activation of PS receptors can regulate its production (94), the regulation of IL-10 synthesis by macrophages engulfing apoptotic cells was not studied in detail. Annexin 1, however, is a known inducer of it in macrophages (128).

Retinoids produced during engulfment to enhance efferocytosis $(122,123)$ can also be released into the surrounding environment and contribute to the TGF- $\beta$-induced development of regulatory T cells. They act so by stabilizing TGF- $\beta$-induced Foxp 3 expression under inflammatory conditions via inhibiting DNA methylation, which otherwise would lead to the silencing of the Foxp3 gene (129). Since regulatory T cells play a central role in preventing autoimmunity, release of TGF- $\beta$ and retinoids by engulfing macrophages strongly contributes to the prevention of an autoimmune response build up following engulfment of apoptotic cells (70).

In addition to producing anti-inflammatory mediators, engulfing macrophages converted from M1 pro-inflammatory macrophages to $\mathrm{M} 2 \mathrm{CD} 11 \mathrm{~b}^{\text {low }}$ macrophages (130) during inflammation are also capable of producing pro-resolving lipid mediators, such as resolvins, protectins, and maresin (131-133). These molecules are synthetized from $\omega$-3 fatty acids via the 12/15-lipoxygenase pathway. Pro-resolving mediators are stimulators of resolution of inflammation. Each facilitates cessation of neutrophil transmigration, microbial phagocytosis, and engulfment of apoptotic neutrophils. They also promote the formation of CD $11 b^{\text {low }}$ macrophages, which in addition to producing pro-resolving lipid mediators, also contribute to the termination of efferocytosis and emigration to lymphoid organs (130) required for the proper termination of the inflammatory program. The conversion to pro-resolving macrophages is also facilitated by the atypical chemokine receptor D6 expressed on the surface of apoptotic neutrophils (134) and by the apoptotic cell uptake itself (135).

And, finally, apoptotic cells also modulate the function of immature iDCs in a way that they force them to secrete molecules which inhibit T cell function. For example, apoptotic cells induce in iDCs the secretion of interferon- $\gamma$ that upregulates $v i a$ autocrine and paracrine mechanisms their indoleamine 2,3-dioxygenase activity leading to the degradation of tryptophan into metabolites that inhibit T cell function (136). Apoptotic cells also induce the release of large amounts of nitric oxide from iDCs that impairs the $\mathrm{T}$ cell response (137). At the same time uptake of apoptotic cells by iDCs triggers TGF- $\beta$ production, which also strongly 
contributes to the immunosuppressive effects of apoptotic cells in vivo (138). Interestingly, plasmacytoid DCs, which themselves cannot engulf apoptotic cells, can also initiate an apoptotic cellinduced anti-inflammatory response. However, their response is dependent on engulfing macrophage-derived soluble factors, including TGF- $\beta$ (139).

\section{CONCLUDING REMARKS}

Apoptotic cell death is a determinant contributing factor to the cell turnover in most of the tissues. The silent removal of apoptotic cells maintains tissue integrity under healthy conditions and its anti-inflammatory nature contributes to the resolution of inflammation (Figure 1). Since the initial discovery that

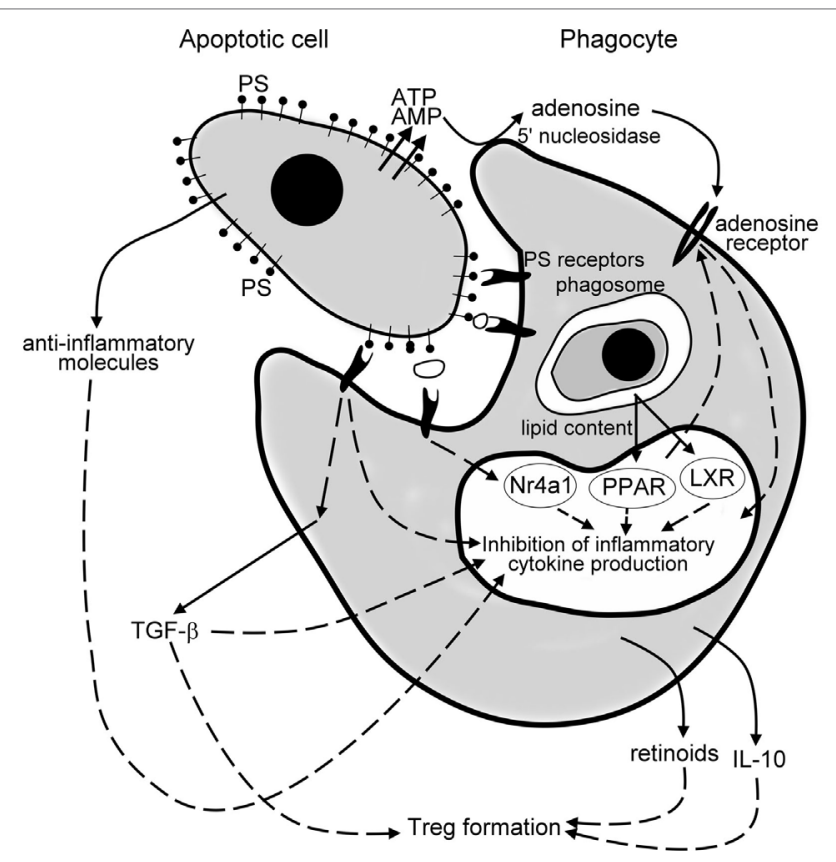

FIGURE 1 | Mechanisms of the anti-inflammatory effects of apoptotic cells. Apoptotic cells release various anti-inflammatory molecules, such as transforming growth factor (TGF)- $\beta$, interleukin (IL)-10, annexin I, thrombospondin-1 (TSP-1), fractalkine to inhibit pro-inflammatory cytokine formation of phagocytes. Once released from the apoptotic cells via a caspase-regulated pannexin channel, ATP is fast degraded to adenosine by the cell surface 5' nucleotidase of engulfing macrophages. Adenosine then triggers macrophage adenosine $\mathrm{A}_{2 \mathrm{~A}}$ receptors to suppress the $\mathrm{NO}$ dependent formation of neutrophil migration factors, or in an inflammatory milieu the lipopolysaccharide (LPS)-induced pro-inflammatory cytokine formation by phagocytes. Apoptotic cells express phosphatidylserine (PS), which activates various PS sensing phagocytic receptors. Many of these receptors initiate such intracellular signaling pathways that interfere with the pro-inflammatory cytokine formation of phagocytes. Following engulfment, the lipid content of the apoptotic cells activate the nuclear lipid sensing receptors [liver $X$ receptors $(L X R s)$ and perixosome proliferator-activated receptors (PPARs)], which in ligated form can also interfere with the NF-кB-driven pro-inflammatory cytokine formation. And, finally, engulfing macrophages release TGF- $\beta$, IL-10, and retinoids, which act in a paracrine or autocrine fashion to amplify and sustain the anti-inflammatory response and strongly contribute to the formation of the regulatory $T$ cells to prevent the development of autoimmunity. apoptotic cells possess potent immune suppressing effects on phagocytes of the immune system, numerous laboratories have initiated successful apoptotic cell-based therapies to induce donor-specific immunosuppression in transplantation (140). Though similar strategies were successful in mouse autoimmune experimental models as well, where apoptotic cells were given at the time of triggering of the disease (141), they would very likely fail in the treatment in chronic inflammatory diseases. This assumption is based on the observation that the establishment and/or progression of an increasing number of chronic inflammatory diseases seem to be coupled to improper phagocytosis of apoptotic cells (142). If the removal of apoptotic cells is delayed, their cell content is released and induces tissue damage leading to long-term inflammation or even to autoimmunity (143). During the past decade, we have understood that the development of chronic inflammation in these cases is related not only to the disturbed removal of dead cells but very likely also to the improper anti-inflammatory regulation that develops as a consequence of the improper clearance. Thus, enhancing efferocytosis and/or the related anti-inflammatory and pro-resolving mechanisms might provide a possibility in the treatment of those human chronic inflammatory diseases, in which impaired clearance of apoptotic cells appears as a driving or contributing force (49).

While the anti-inflammatory nature of apoptotic cell clearance is protective in healthy tissues, high PS expression of apoptotic tumor cells might promote tumor growth via suppressing immunity (93). Indeed, increasing evidence indicate that systemic administration of annexin A5 or other PS ligands that cover PS and block PS-mediated apoptotic tumor cell signaling may slow down tumor progression via interfering with the immunosuppressive properties of apoptotic tumor cells and tumor-derived microvesicles $(144,145)$. Thus, it was suggested that in combination with radio- or chemotherapy, annexin A5 could be used as a natural adjuvant to increase the immunogenicity of dying tumor cells thereby promoting the development of an anti-tumor immune response $(93,146)$.

And, finally, it is worth to note that though apoptotic cells are generally anti-inflammatory, cancer cells undergoing apoptosis in response to specific anticancer therapies can be immunogenic, if they emit precise DAMPs in a spatiotemporally defined fashion. Some of these DAMPs activate DCs during engulfment, which then can prime $\mathrm{CD} 4^{+} \mathrm{T}$ cells, $\mathrm{CD} 8^{+}$cytotoxic lymphocytes, and $\gamma \delta \mathrm{T}$ lymphocytes against one or several tumor-associated antigens (147).

\section{AUTHOR CONTRIBUTIONS}

ZSzondy, EG, BK, KK, and ZSarang contributed to the experiments related to the topic and write the paper together.

\section{FUNDING}

This study was supported by Hungarian National Research Fund (OTKA 104228) and by the GINOP-2.3.2-15-2016-00006 project (co-financed by the European Union and the European Regional Development Fund). 


\section{REFERENCES}

1. Hart SP, Dransfield I, Rossi AG. Phagocytosis of apoptotic cells. Methods (2008) 44:280-5. doi:10.1016/j.ymeth.2007.11.009

2. Rigamonti E, Zordan P, Sciorati C, Rovere-Querini P, Brunelli S. Macrophage plasticity in skeletal muscle repair. Biomed Res Int (2014) 2014:560629. doi:10.1155/2014/560629

3. Thorp EB. Contrasting inflammation resolution during atherosclerosis and post myocardial infarction at the level of monocyte/macrophage phagocytic clearance. Front Immunol (2012) 3:39. doi:10.3389/fimmu.2012.00039

4. Wan E, Yeap XY, Dehn S, Terry R, Novak M, Zhang S, et al. Enhanced efferocytosis of apoptotic cardiomyocytes through myeloid-epithelialreproductive tyrosine kinase links acute inflammation resolution to cardiac repair after infarction. Circ Res (2013) 113:1004-12. doi:10.1161/ CIRCRESAHA.113.301198

5. Savill J, Dransfield I, Gregory C, Haslett C. A blast from the past: clearance of apoptotic cells regulates immune responses. Nat Rev Immunol (2002) 2:965-75. doi:10.1038/nri957

6. Truman LA, Ford CA, Pasikowska M, Pound JD, Wilkinson SJ, Dumitriu IE, et al. CX3CL1/fractalkine is released from apoptotic lymphocytes to stimulate macrophage chemotaxis. Blood (2008) 112:5026-36. doi:10.1182/ blood-2008-06-162404

7. Lauber K, Bohn E, Kröber SM, Xiao YJ, Blumenthal SG, Lindemann RK, et al. Apoptotic cells induce migration of phagocytes via caspase-3-mediated release of a lipid attraction signal. Cell (2003) 113:717-30. doi:10.1016/ S0092-8674(03)00422-7

8. Gude DR, Alvarez SE, Paugh SW, Mitra P, Yu J, Griffiths R, et al. Apoptosis induces expression of sphingosine kinase 1 to release sphingosine-1-phosphate as a "come-and-get-me" signal. FASEB J (2008) 22:2629-38. doi:10.1096/ fi.08-107169

9. Moodley Y, Rigby P, Bundell C, Bunt S, Hayashi H, Misso N, et al. Macrophage recognition and phagocytosis of apoptotic fibroblasts is critically dependent on fibroblast-derived thrombospondin 1 and CD36. Am J Pathol (2003) 162:771-9. doi:10.1016/S0002-9440(10)63874-6

10. Elliott MR, Chekeni FB, Trampont PC, Lazarowski ER, Kadl A, Walk SF, et al. Nucleotides released by apoptotic cells act as a find-me signal to promote phagocytic clearance. Nature (2009) 461:282-6. doi:10.1038/nature08296

11. Knies UE, Behrensdorf HA, Mitchell CA, Deutsch U, Risau W, Drexler HC, et al. Regulation of endothelial monocyte-activating polypeptide II release by apoptosis. Proc Natl Acad Sci U S A (1998) 95:12322-7. doi:10.1073/ pnas.95.21.12322

12. Cullen SP, Henry CM, Kearney CJ, Logue SE, Feoktistova M, Tynan GA, et al. Fas/CD95-induced chemokines can serve as "find-me" signals for apoptotic cells. Mol Cell (2013) 49:1034-48. doi:10.1016/j.molcel.2013.01.025

13. Wakasugi K, Schimmel P. Two distinct cytokines released from a human aminoacyl-tRNA synthetase. Science (1999) 284:147-51. doi:10.1126/ science.284.5411.147

14. Nishiura H, Shibuya Y, Yamamoto T. S19 ribosomal protein cross-linked dimer causes monocyte-predominant infiltration by means of molecular mimicry to complement C5a. Lab Invest (1998) 78:1615-23.

15. Ravichandran KS. Find-me and eat-me signals in apoptotic cell clearance: progress and conundrums. JExp Med (2010) 207:1807-17. doi:10.1084/ jem.20101157

16. Fadok VA, Voelker DR, Campbell PA, Cohen JJ, Bratton DL, Henson PM. Exposure of phosphatidylserine on the surface of apoptotic lymphocytes triggers specific recognition and removal by macrophages. J Immunol (1992) 148:2207-16

17. Miyanishi M, Tada K, Koike M, Uchiyama Y, Kitamura T, Nagata S. Identification of Tim4 as a phosphatidylserine receptor. Nature (2007) 450:435-9. doi:10.1038/nature06307

18. Park SY, Jung MY, Kim HJ, Lee SJ, Kim SY, Lee BH, et al. Rapid cell corpse clearance by stabilin-2, a membrane phosphatidylserine receptor. Cell Death Differ (2008) 15:192-201. doi:10.1038/sj.cdd.4402242

19. Park D, Tosello-Trampont AC, Elliott MR, Lu M, Haney LB, Ma Z, et al. BAI1 is an engulfment receptor for apoptotic cells upstream of the ELMO/Dock180/ Rac module. Nature (2007) 450:430-4. doi:10.1038/nature06329

20. Scott RS, McMahon EJ, Pop SM, Reap EA, Caricchio R, Cohen PL, et al. Phagocytosis and clearance of apoptotic cells is mediated by MER. Nature (2001) 411:207-11. doi:10.1038/35079659
21. Ramirez-Ortiz ZG, Pendergraft WF III, Prasad A, Byrne MH, Iram T, Blanchette CJ, et al. The scavenger receptor SCARF1 mediates the clearance of apoptotic cells and prevents autoimmunity. Nat Immunol (2013) 14:917-26. doi: $10.1038 /$ ni. 2670

22. Savill J, Hogg N, Ren Y, Haslett C. Thrombospondin cooperates with CD36 and the vitronectin receptor in macrophage recognition of neutrophils undergoing apoptosis. J Clin Invest (1992) 90:1513-22. doi:10.1172/ JCI116019

23. Szondy Z, Sarang Z, Molnar P, Nemeth T, Piacentini M, Mastroberardino PG, et al. Transglutaminase 2-/- mice reveal a phagocytosis-associated crosstalk between macrophages and apoptotic cells. Proc Natl Acad Sci U S A (2003) 100:7812-7. doi:10.1073/pnas.0832466100

24. Chen J, Carey K, Godowski PJ. Identification of Gas6 as a ligand for Mer, a neural cell adhesion molecule related receptor tyrosine kinase implicated in cellular transformation. Oncogene (1997) 14:2033-9. doi:10.1038/sj.onc. 1201039

25. Hall MO, Obin MS, Heeb MJ, Burgess BL, Abrams TA. Both protein S and Gas6 stimulate outer segment phagocytosis by cultured rat retinal pigment epithelial cells. Exp Eye Res (2005) 81:581-91. doi:10.1016/j.exer.2005.03.017

26. Hanayama R, Tanaka M, Miwa K, Shinohara A, Iwamatsu A, Nagata S. Identification of a factor that links apoptotic cells to phagocytes. Nature (2002) 417:182-7. doi:10.1038/417182a

27. Tóth B, Garabuczi E, Sarang Z, Vereb G, Vámosi G, Aeschlimann D, et al. Transglutaminase 2 is needed for the formation of an efficient phagocyte portal in macrophages engulfing apoptotic cells. J Immunol (2009) 182:2084-92. doi:10.4049/jimmunol.0803444

28. Jun JI, Kim KH, Lau LF. The matricellular protein CCN1 mediates neutrophil efferocytosis in cutaneous wound healing. Nat Commun (2015) 6:7386. doi:10.1038/ncomms 8386

29. Martin M, Leffler J, Blom AM. Annexin A2 and A5 serve as new ligands for C1q on apoptotic cells. J Biol Chem (2012) 287:33733-44. doi:10.1074/jbc. M112.341339

30. Ogden CA, deCathelineau A, Hoffmann PR, Bratton D, Ghebrehiwet B, Fadok VA, et al. C1q and mannose binding lectin engagement of cell surface calreticulin and CD91 initiates macropinocytosis and uptake of apoptotic cells. J Exp Med (2001) 194:781-95. doi:10.1084/jem.194.6.781

31. Gardai SJ, McPhillips KA, Frasch SC, Janssen WJ, Starefeldt A, MurphyUllrich JE, et al. Cell-surface calreticulin initiates clearance of viable or apoptotic cells through trans-activation of LRP on the phagocyte. Cell (2005) 123:321-34. doi:10.1016/j.cell.2005.08.032

32. Scannell M, Flanagan MB, deStefani A, Wynne KJ, Cagney G, Godson C, et al. Annexin-1 and peptide derivatives are released by apoptotic cells and stimulate phagocytosis of apoptotic neutrophils by macrophages. J Immunol (2007) 178:4595-605. doi:10.4049/jimmunol.178.7.4595

33. Maderna P, Cottell DC, Toivonen T, Dufton N, Dalli J, Perretti M, et al. FPR2/ ALX receptor expression and internalization are critical for lipoxin A4 and annexin-derived peptide-stimulated phagocytosis. FASEB J (2010) 24:4240-9. doi:10.1096/fj.10-159913

34. Kinchen JM, Cabello J, Klingele D, Wong K, Feichtinger R, Schnabel H, et al. Two pathways converge at CED-10 to mediate actin rearrangement and corpse removal in C. elegans. Nature (2005) 434:93-9. doi:10.1038/nature03263

35. Xu M, Liu Y, Zhao L, Gan Q, Wang X, Yang C. The lysosomal cathepsin protease CPL-1 plays a leading role in phagosomal degradation of apoptotic cells in Caenorhabditis elegans. Mol Biol Cell (2014) 25(13):2071-83. doi:10.1091/ mbc.E14-01-0015

36. Kawane K, Ohtani M, Miwa K, Kizawa T, Kanbara Y, Yoshioka Y, et al. Chronic polyarthritis caused by mammalian DNA that escapes from degradation in macrophages. Nature (2006) 443:998-1002. doi:10.1038/nature05245

37. Silva E, Au-Yeung HW, Van Goethem E, Burden J, Franc NC. Requirement for a Drosophila E3-ubiquitin ligase in phagocytosis of apoptotic cells. Immunity (2007) 27:585-96. doi:10.1016/j.immuni.2007.08.016

38. Kidani Y, Bensinger SJ. Liver X receptor and peroxisome proliferator-activated receptor as integrators of lipid homeostasis and immunity. Immunol Rev (2012) 249:72-83. doi:10.1111/j.1600-065X.2012.01153.x

39. Evans RM, Mangelsdorf DJ. Nuclear receptors, RXR, and the Big Bang. Cell (2014) 157:255-66. doi:10.1016/j.cell.2014.03.012

40. Janowski BA, Willy PJ, Devi TR, Falck JR, Mangelsdorf DJ. An oxysterol signalling pathway mediated by the nuclear receptor LXR alpha. Nature (1996) 383:728-31. doi: $10.1038 / 383728 \mathrm{a} 0$ 
41. Fu X, Menke JG, Chen Y, Zhou G, MacNaul KL, Wright SD, et al. 27hydroxycholesterol is an endogenous ligand for liver $\mathrm{X}$ receptor in cholesterolloaded cells. J Biol Chem (2001) 276:38378-87. doi:10.1074/jbc.M105805200

42. Castrillo A, Tontonoz P. Nuclear receptors in macrophage biology: at the crossroads of lipid metabolism and inflammation. Annu Rev Cell Dev Biol (2004) 20:455-80. doi:10.1146/annurev.cellbio.20.012103.134432

43. Calkin AC, Tontonoz P. Transcriptional integration of metabolism by the nuclear sterol-activated receptors LXR and FXR. Nat Rev Mol Cell Biol (2012) 13:213-24. doi:10.1038/nrm3312

44. Desvergne B, Wahli W. Peroxisome proliferator-activated receptors: nuclear control of metabolism. Endocr Rev (1999) 20:649-88. doi:10.1210/er.20.5.649

45. Wang YX, Lee CH, Tiep S, Yu RT, Ham J, Kang H, et al. Peroxisomeproliferator-activated receptor delta activates fat metabolism to prevent obesity. Cell (2003) 113:159-70. doi:10.1016/S0092-8674(03)00269-1

46. Cvetanovic M, Ucker DS. Innate immune discrimination of apoptotic cells: repression of proinflammatory macrophage transcription is coupled to specific recognition. J Immunol (2004) 172:880-9. doi:10.4049/ jimmunol.172.2.880

47. Voll RE, Herrmann M, Roth EA, Stach C, Kalden JR, Girkontaite I. Immunosuppressive effects of apoptotic cells. Nature (1997) 390:350-1. doi: $10.1038 / 37022$

48. Fadok VA, Bratton DL, Konowal A, Freed PW, Westcott JY, Henson PM. Macrophages that have ingested apoptotic cells in vitro inhibit proinflammatory cytokine production through autocrine/paracrine mechanisms involving TGF-beta, PGE2, and PAF. JClin Invest (1998) 101:890-8. doi:10.1172/ JCI1112

49. Szondy Z, Garabuczi E, Joós G, Tsay GJ, Sarang Z. Impaired clearance of apoptotic cells in chronic inflammatory diseases: therapeutic implications. Front Immunol (2014) 5:354. doi:10.3389/fimmu.2014.00354

50. Martin SJ, Henry CM, Cullen SP. A perspective on mammalian caspases as positive and negative regulators of inflammation. Mol Cell (2012) 46:387-97. doi:10.1016/j.molcel.2012.04.026

51. Cocco R, Ucker DS. Distinct modes of macrophage recognition for apoptotic and necrotic cells are not specified exclusively by phosphatidylserine exposure. Mol Biol Cell (2001) 12:919-30. doi:10.1091/mbc.12.4.919

52. Birge RB, Ucker DS. Innate apoptotic immunity: the calming touch of death. Cell Death Differ (2008) 15:1096-102. doi:10.1038/cdd.2008.58

53. Marichal T, Ohata K, Bedoret D, Mesnil C, Sabatel C, Kobiyama K, et al. DNA released from dying host cells mediates aluminum adjuvant activity. Nat Med (2011) 17:996-1002. doi:10.1038/nm.2403

54. Enari M, Sakahira H, Yokoyama H, Okawa K, Iwamatsu A, Nagata S. A caspase-activated DNase that degrades DNA during apoptosis, and its inhibitor ICAD. Nature (1998) 391:43-50. doi:10.1038/34112

55. Kawane K, Fukuyama H, Yoshida H, Nagase H, Ohsawa Y, Uchiyama Y, et al. Impaired thymic development in mouse embryos deficient in apoptotic DNA degradation. Nat Immunol (2003) 4:138-44. doi:10.1038/ni881

56. Okabe Y, Sano T, Nagata S. Regulation of the innate immune response by threonine-phosphatase of eyes absent. Nature (2009) 460:520-4. doi:10.1038/ nature 08138

57. Rajput A, Kovalenko A, Bogdanov K, Yang SH, Kang TB, Kim JC, et al. RIG-I RNA helicase activation of IRF3 transcription factor is negatively regulated by caspase-8-mediated cleavage of the RIP1 protein. Immunity (2011) 34:340-51. doi:10.1016/j.immuni.2010.12.018

58. Rongvaux A, Jackson R, Harman CC, Li T, West AP, de Zoete MR, et al. Apoptotic caspases prevent the induction of type I interferons by mitochondrial DNA. Cell (2014) 159:1563-77. doi:10.1016/j.cell.2014.11.037

59. Scaffidi P, Misteli T, Bianchi ME. Release of chromatin protein HMGB1 by necrotic cells triggers inflammation. Nature (2002) 418:191-5. doi:10.1038/ nature 00858

60. Kazama H, Ricci JE, Herndon JM, Hoppe G, Green DR, Ferguson TA. Induction of immunological tolerance by apoptotic cells requires caspasedependent oxidation of high-mobility group box-1 protein. Immunity (2008) 29:21-32. doi:10.1016/j.immuni.2008.05.013

61. Lüthi AU, Cullen SP, McNeela EA, Duriez PJ, Afonina IS, Sheridan C, et al. Suppression of interleukin-33 bioactivity through proteolysis by apoptotic caspases. Immunity (2009) 31:84-98. doi:10.1016/j.immuni.2009.05.007

62. Chen W, Frank ME, Jin W, Wahl SM. TGF- $\beta$ released by apoptotic T cells contributes to an immunosuppressive milieu. Immunity (2001) 14:715-25. doi:10.1016/S1074-7613(01)00147-9
63. Li MO, Wan YY, Sanjabi S, Robertson AK, Flavell RA. Transforming growth factor-beta regulation of immune responses. Annu Rev Immunol (2006) 24:99-146. doi:10.1146/annurev.immunol.24.021605.090737

64. Shull MM, Ormsby I, Kier AB, Pawlowski S, Diebold RJ, Yin M, et al. Targeted disruption of the mouse transforming growth factor-beta 1 gene results in multifocal inflammatory disease. Nature (1992) 359:693-9. doi:10.1038/359693a0

65. Kulkarni AB, Huh CG, Becker D, Geiser A, Lyght M, Flanders KC, et al. Transforming growth factor beta 1 null mutation in mice causes excessive inflammatory response and early death. Proc Natl Acad Sci U S A (1993) 90:770-4. doi:10.1073/pnas.90.2.770

66. Wahl SM. Transforming growth factor beta (TGF-beta) in inflammation: a cause and a cure. J Clin Immunol (1992) 12:61-74. doi:10.1007/BF00918135

67. Gamble JR, Vadas MA. Endothelial adhesiveness for blood neutrophils is inhibited by transforming growth factor-beta. Science (1988) 242:97-9. doi:10.1126/science. 3175638

68. Tsunawaki S, Sporn M, Ding A, Nathan C. Deactivation of macrophages by transforming growth factor-beta. Nature (1988) 334:260-2 doi:10.1038/334260a0

69. Chen W, Jin W, Hardegen N, Lei KJ, Li L, Marinos N, et al. Conversion of peripheral CD4+CD25- naive $\mathrm{T}$ cells to $\mathrm{CD} 4+\mathrm{CD} 25+$ regulatory $\mathrm{T}$ cells by TGF-beta induction of transcription factor Foxp3. J Exp Med (2003) 198:1875-86. doi:10.1084/jem.20030152

70. Sakaguchi S, Miyara M, Costantino CM, Hafler DA. FOXP3+ regulatory T cells in the human immune system. Nat Rev Immunol (2010) 10:490-500. doi: $10.1038 /$ nri2785

71. Konkel JE, Jin W, Abbatiello B, Grainger JR, Chen W. Thymocyte apoptosis drives the intrathymic generation of regulatory T cells. Proc Natl Acad Sci U S A (2014) 111:E465-73. doi:10.1073/pnas.1320319111

72. Gao Y, Herndon JM, Zhang H, Griffith TS, Ferguson TA. Antiinflammatory effects of CD95 ligand (FasL)-induced apoptosis. J Exp Med (1998) 188: 887-96. doi:10.1084/jem.188.5.887

73. Levings MK, Bacchetta R, Schulz U, Roncarolo MG. The role of IL-10 and TGF-beta in the differentiation and effector function of T regulatory cells. Int Arch Allergy Immunol (2002) 129:263-76. doi:10.1159/000067596

74. Pupjalis D, Goetsch J, Kottas DJ, Gerke V, Rescher U. Annexin A1 released from apoptotic cells acts through formyl peptide receptors to dampen inflammatory monocyte activation via JAK/STAT/SOCS signalling. EMBO Mol Med (2011) 3:102-14. doi:10.1002/emmm.201000113

75. Bournazou I, Pound JD, Duffin R, Bournazos S, Melville LA, Brown SB, et al. Apoptotic human cells inhibit migration of granulocytes via release of lactoferrin. J Clin Invest (2009) 119:20-32. doi:10.1172/JCI36226

76. Bournazou I, Mackenzie KJ, Duffin R, Rossi AG, Gregory CD. Inhibition of eosinophil migration by lactoferrin. Immunol Cell Biol (2010) 88:220-3 doi:10.1038/icb.2009.86

77. Truman LA, Ogden CA, Howie SE, Gregory CD. Macrophage chemotaxis to apoptotic Burkitt's lymphoma cells in vitro: role of CD14 and CD36. Immunobiology (2004) 209:21-30. doi:10.1016/j.imbio.2004.02.001

78. Lopez-Dee Z, Pidcock K, Gutierrez LS. Thrombospondin-1: multiple paths to inflammation. Mediators Inflamm (2011) 2011:296069. doi: $10.1155 / 2011 / 296069$

79. Schultz-Cherry S, Chen H, Mosher DF, Misenheimer TM, Krutzsch HC, Roberts DD, et al. Regulation of transforming growth factor-beta activation by discrete sequences of thrombospondin 1. J Biol Chem (1995) 270:7304-10. doi:10.1074/jbc.270.13.7304

80. Krispin A, Bledi Y, Atallah M, Trahtemberg U, Verbovetski I, Nahari E, et al. Apoptotic cell thrombospondin-1 and heparin-binding domain lead to dendritic-cell phagocytic and tolerizing states. Blood (2006) 108:3580-9. doi:10.1182/blood-2006-03-013334

81. Zujovic V, Benavides J, Vigé X, Carter C, Taupin V. Fractalkine modulates TNF-alpha secretion and neurotoxicity induced by microglial activation. Glia (2000) 29:305-15. doi:10.1002/ (SICI)1098-1136(20000215)29:4<305::AID-GLIA2>3.0.CO;2-V

82. Huang LS, Hung ND, Sok DE, Kim MR. Lysophosphatidylcholine containing docosahexaenoic acid at the sn-1 position is anti-inflammatory. Lipids (2010) 45:225-36. doi:10.1007/s11745-010-3392-5

83. Sandilos JK, Chiu YH, Chekeni FB, Armstrong AJ, Walk SF, Ravichandran KS, et al. Pannexin 1, an ATP release channel, is activated by caspase cleavage of its pore-associated C-terminal autoinhibitory region. J Biol Chem (2012) 287:11303-11. doi:10.1074/jbc.M111.323378 
84. Yamaguchi H, Maruyama T, Urade Y, Nagata S. Immunosuppression via adenosine receptor activation by adenosine monophosphate released from apoptotic cells. Elife (2014) 3:e02172. doi:10.7554/eLife.02172

85. Sándor K, Pallai A, Duró E, Legendre P, Couillin I, Sághy T, et al. Adenosine produced from adenine nucleotides through an interaction between apoptotic cells and engulfing macrophages contributes to the appearance of transglutaminase 2 in dying thymocytes. Amino Acids (2017) 115:124-32. doi:10.1007/s00726-016-2257-5

86. Köröskényi K, Duró E, Pallai A, Sarang Z, Kloor D, Ucker DS, et al. Involvement of adenosine A2A receptors in engulfment-dependent apoptotic cell suppression of inflammation. J Immunol (2011) 186:7144-55. doi:10.4049/jimmunol.1002284

87. Duró E, Pallai A, Köröskényi K, Sarang Z, Szondy Z. Adenosine A3 receptors negatively regulate the engulfment-dependent apoptotic cell suppression of inflammation. Immunol Lett (2014) 162:292-301. doi:10.1016/j. imlet.2014.06.014

88. Joós G, Jákim J, Kiss B, Szamosi R, Papp T, Felszeghy S, et al. Involvement of adenosine $\mathrm{A} 3$ receptors in the chemotactic navigation of macrophages towards apoptotic cells. Immunol Lett (2017) 183:62-72. doi:10.1016/j. imlet.2017.02.002

89. Haskó G, Kuhe DG, Chen JF, Schwarzschild MA, Deitch EA, Mabley JG, et al. Adenosine inhibits IL-12 and TNF-[alpha] production via adenosine A2a receptor-dependent and independent mechanisms. FASEB J (2000) 14:2065-74. doi:10.1096/fj.99-0508com

90. Crean D, Cummins EP, Bahar B, Mohan H, McMorrow JP, Murphy EP. Adenosine modulates NR4A orphan nuclear receptors to attenuate hyperinflammatory responses in monocytic cells. J Immunol (2015) 195:1436-48. doi:10.4049/jimmunol.1402039

91. Köröskényi K, Kiss B, Szondy Z. Adenosine A2A receptor signaling attenuates LPS-induced pro-inflammatory cytokine formation of mouse macrophages by inducing the expression of DUSP1. Biochim Biophys Acta (2016) 1863:1461-71. doi:10.1016/j.bbamcr.2016.04.003

92. Krahling S, Callahan MK, Williamson P, Schlegel RA. Exposure of phosphatidylserine is a general feature in the phagocytosis of apoptotic lymphocytes by macrophages. Cell Death Differ (1999) 6:183-9. doi:10.1038/ sj.cdd. 4400473

93. Birge RB, Boeltz S, Kumar S, Carlson J, Wanderley J, Calianese D, et al. Phosphatidylserine is a global immunosuppressive signal in efferocytosis, infectious disease, and cancer. Cell Death Differ (2016) 23:962-78. doi:10.1038/cdd.2016.11

94. Huynh ML, Fadok VA, Henson PM. Phosphatidylserine-dependent ingestion of apoptotic cells promotes TGF-betal secretion and the resolution of inflammation. J Clin Invest (2002) 109:41-50. doi:10.1172/ JCI0211638

95. Kim S, Elkon KB, Ma X. Transcriptional suppression of interleukin-12 gene expression following phagocytosis of apoptotic cells. Immunity (2004) 21:643-53. doi:10.1016/j.immuni.2004.09.009

96. Ipseiz N, Uderhardt S, Scholtysek C, Steffen M, Schabbauer G, Bozec A, et al. The nuclear receptor Nr4al mediates anti-inflammatory effects of apoptotic cells. J Immunol (2014) 192:4852-8. doi:10.4049/jimmunol.1303377

97. Park D, Hochreiter-Hufford A, Ravichandran KS. The phosphatidylserine receptor TIM-4 does not mediate direct signaling. Curr Biol (2009) 19:346-51. doi:10.1016/j.cub.2009.01.042

98. Tibrewal N, Wu Y, D’Mello V, Akakura R, George TC, Varnum B, et al. Autophosphorylation docking site Tyr-867 in Mer receptor tyrosine kinase allows for dissociation of multiple signaling pathways for phagocytosis of apoptotic cells and down-modulation of lipopolysaccharide-inducible NF-kappaB transcriptional activation. J Biol Chem (2008) 283:3618-27. doi:10.1074/jbc.M706906200

99. Lucas M, Stuart LM, Zhang A, Hodivala-Dilke K, Febbraio M, Silverstein R, et al. Requirements for apoptotic cell contact in regulation of macrophage responses. J Immunol (2006) 177:4047-54. doi:10.4049/jimmunol.177.6.4047

100. Lemke G. Biology of the TAM receptors. Cold Spring Harb Perspect Biol (2013) 5:a009076. doi:10.1101/cshperspect.a009076

101. Falasca L, Iadevaia V, Ciccosanti F, Melino G, Serafino A, Piacentini M. Tansglutaminase type II is a key element in the regulation of the antiinflammatory response elicited by apoptotic cell engulfment. J Immunol (2005) 174:7330-40. doi:10.4049/jimmunol.174.11.7330
102. Nunes I, Shapiro RL, Rifkin DB. Characterization of latent TGF-beta activation by murine peritoneal macrophages. J Immunol (1995) 155:1450-9.

103. Gallucci S, Lolkema M, Matzinger P. Natural adjuvants: endogenous activators of dendritic cells. Nat Med (1999) 5:1249-55. doi:10.1038/15200

104. Sauter B, Albert M, Francisco L, Larsson M, Somersan S, Bhardwaj N. Consequences of cell death: exposure to necrotic tumor cells, but not primary tissue cells or apoptotic cells, induces the maturation of immunostimulatory dendritic cells. J Exp Med (2000) 191:423-35. doi:10.1084/jem.191.3.423

105. Urban BC, Willcox N, Roberts DJ. A role for CD36 in the regulation of dendritic cell function. Proc Natl Acad Sci U S A (2001) 98:8750-5. doi:10.1073/ pnas. 151028698

106. Stuart LM, Lucas M, Simpson C, Lamb J, Savill J, Lacy-Hulbert A. Inhibitory effects of apoptotic cell ingestion upon endotoxin-driven myeloid dendritic cell maturation. JImmunol (2002) 168:1627-35. doi:10.4049/ jimmunol.168.4.1627

107. Verbovetski I, Bychkov H, Trahtemberg U, Shapira I, Hareuveni M, BenTal O, et al. Opsonization of apoptotic cells by autologous iC3b facilitates clearance by immature dendritic cells, down-regulates DR and CD86, and up-regulates CC chemokine receptor 7. J Exp Med (2002) 196:1553-61. doi:10.1084/jem.20020263

108. Takahashi M, Kobayashi Y. Cytokine production in association with phagocytosis of apoptotic cells by immature dendritic cells. Cell Immunol (2003) 226:105-15. doi:10.1016/j.cellimm.2003.11.008

109. Chen X, Doffek K, Sugg SL, Shilyansky J. Phosphatidylserine regulates the maturation of human dendritic cells. J Immunol (2004) 173:2985-94. doi:10.4049/jimmunol.173.5.2985

110. Sen P, Wallet MA, Yi Z, Huang Y, Henderson M, Mathews CE, et al. Apoptotic cells induce Mer tyrosine kinase-dependent blockade of NF- $\kappa \mathrm{B}$ activation in dendritic cells. Blood (2007) 109:653-60. doi:10.1182/blood-2006-04-017368

111. Rothlin CV, Ghosh S, Zuniga EI, Oldstone MB, Lemke G. TAM receptors are pleiotropic inhibitors of the innate immune response. Cell (2007) 131:1124-36. doi:10.1016/j.cell.2007.10.034

112. Rangachari M, Zhu C, Sakuishi K, Xiao S, Karman J, Chen A, et al. Bat3 promotes $\mathrm{T}$ cell responses and autoimmunity by repressing Tim-3-mediated cell death and exhaustion. Nat Med (2012) 18:1394-400. doi:10.1038/nm.2871

113. Jaillon S, Jeannin P, Hamon Y, Frémaux I, Doni A, Bottazzi B, et al. Endogenous PTX3 translocates at the membrane of late apoptotic human neutrophils and is involved in their engulfment by macrophages. Cell Death Differ (2009) 16:465-74. doi:10.1038/cdd.2008.173

114. Pilling D, Galvis-Carvajal E, Karhadkar TR, Cox N, Gomer RH. Monocyte differentiation and macrophage priming are regulated differentially by pentraxins and their ligands. BMC Immunol (2017) 18:30. doi:10.1186/ s12865-017-0214-Z

115. Klaas M, Crocker PR. Sialoadhesin in recognition of self and non-self. Semin Immunopathol (2012) 34:353-64. doi:10.1007/s00281-012-0310-3

116. Ravishankar B, Liu H, Shinde R, Chaudhary K, Xiao W, Bradley J, et al. The amino acid sensor GCN2 inhibits inflammatory responses to apoptotic cells promoting tolerance and suppressing systemic autoimmunity. Proc Natl Acad Sci U S A (2015) 112:10774-9. doi:10.1073/pnas.1504276112

117. Lee CH, Chawla A, Urbiztondo N, Liao D, Boisvert WA, Evans RM, et al. Transcriptional repression of atherogenic inflammation: modulation by PPARdelta. Science (2003) 302:453-7. doi:10.1126/science.1087344

118. A-Gonzalez N, Bensinger SJ, Hong C, Beceiro S, Bradley MN, Zelcer N, et al. Apoptotic cells promote their own clearance and immune tolerance through activation of the nuclear receptor LXR. Immunity (2009) 31:245-58. doi:10.1016/j.immuni.2009.06.018

119. Mukundan L, Odegaard JI, Morel CR, Heredia JE, Mwangi JW, RicardoGonzalez RR, et al. PPAR-delta senses and orchestrates clearance of apoptotic cells to promote tolerance. Nat Med (2009) 15:1266-72. doi:10.1038/nm.2048

120. Rőszer T, Menéndez-Gutiérrez MP, Lefterova MI, Alameda D, Núñez V, Lazar MA, et al. Autoimmune kidney disease and impaired engulfment of apoptotic cells in mice with macrophage peroxisome proliferator-activated receptor gamma or retinoid X receptor alpha deficiency. J Immunol (2011) 186:621-31. doi:10.4049/jimmunol.1002230

121. Rébé C, Raveneau M, Chevriaux A, Lakomy D, Sberna AL, Costa A, et al. Induction of transglutaminase 2 by a liver $\mathrm{X}$ receptor/retinoic acid receptor alpha pathway increases the clearance of apoptotic cells by human macrophages. Circ Res (2009) 105:393-401. doi:10.1161/CIRCRESAHA.109.201855 
122. Sarang Z, Joós G, Garabuczi É, Rühl R, Gregory CD, Szondy Z. Macrophages engulfing apoptotic cells produce nonclassical retinoids to enhance their phagocytic capacity. J Immunol (2014) 192:5730-8. doi:10.4049/ jimmunol.1400284

123. Garabuczi É, Kiss B, Felszeghy S, Tsay GJ, Fésüs L, Szondy Z. Retinoids produced by macrophages engulfing apoptotic cells contribute to the appearance of transglutaminase 2 in apoptotic thymocytes. Amino Acids (2013) 44:235-44. doi:10.1007/s00726-011-1119-4

124. Serhan CN, Chiang N, Dalli J, Levy BD. Lipid mediators in the resolution of inflammation. Lipid mediators in the resolution of inflammation. Cold Spring Harb Perspect Biol (2014) 7:a016311. doi:10.1101/cshperspect. a016311

125. Li XM, Zhang S, He XS, Guo PD, Lu XX, Wang JR, et al. Nur77-mediated TRAF6 signalling protects against LPS-induced sepsis in mice. J Inflamm (Lond) (2016) 13:4. doi:10.1186/s12950-016-0112-9

126. Li L, Liu Y, Chen HZ, Li FW, Wu JF, Zhang HK, et al. Impeding the interaction between Nur77 and p38 reduces LPS-induced inflammation. Nat Chem Biol (2015) 11:339-46. doi:10.1038/nchembio.1788

127. Freire-de-Lima CG, Xiao YQ, Gardai SJ, Bratton DL, Schiemann WP, Henson PM. Apoptotic cells, through transforming growth factor-beta, coordinately induce anti-inflammatory and suppress pro-inflammatory eicosanoid and NO synthesis in murine macrophages. J Biol Chem (2006) 281:38376-84. doi:10.1074/jbc.M605146200

128. Parente L, Solito E. Annexin 1: more than an anti-phospholipase protein. Inflamm Res (2004) 53:125-32. doi:10.1007/s00011-003-1235-Z

129. Liu ZM, Wang KP, Ma J, Guo Zheng S. The role of all-trans retinoic acid in the biology of Foxp3+ regulatory T cells. Cell Mol Immunol (2015) 12:553-7. doi:10.1038/cmi.2014.133

130. Schif-Zuck S, Gross N, Assi S, Rostoker R, Serhan CN, Ariel A. Saturatedefferocytosis generates pro-resolving CD11b low macrophages: modulation by resolvins and glucocorticoids. Eur J Immunol (2010) 41:366-79. doi:10.1002/eji.201040801

131. Godson C, Mitchell S, Harvey K, Petasis NA, Hogg N, Brady HR. Cutting edge: lipoxins rapidly stimulate nonphlogistic phagocytosis of apoptotic neutrophils by monocyte-derived macrophages. J Immunol (2000) 164:1663-7. doi:10.4049/jimmunol.164.4.1663

132. Serhan CN, Chiang N, Van Dyke TE. Resolving inflammation: dual antiinflammatory and pro-resolution lipid mediators. Nat Rev Immunol (2008) 8:349-61. doi:10.1038/nri2294

133. Serhan CN, Chiang N. Resolution phase lipid mediators of inflammation: agonists of resolution. Curr Opin Pharmacol (2013) 4:632-40. doi:10.1016/j. coph.2013.05.012

134. Pashover-Schallinger E, Aswad M, Schif-Zuck S, Shapiro H, Singer P, Ariel A. The atypical chemokine receptor D6 controls macrophage efferocytosis and cytokine secretion during the resolution of inflammation. FASEB J (2012) 26:3891-900. doi:10.1096/fj.11-194894

135. Arnold L, Henry A, Poron F, Baba-Amer Y, van Rooijen N, Plonquet A, et al. Inflammatory monocytes recruited after skeletal muscle injury switch into antiinflammatory macrophages to support myogenesis. J Exp Med (2007) 204:1057-69. doi:10.1084/jem.20070075
136. Williams CA, Harry RA, McLeod JD. Apoptotic cells induce dendritic cell-mediated suppression via interferon- $\gamma$-induced IDO. Immunology (2007) 124:89-101. doi:10.1111/j.1365-2567.2007.02743.x

137. Ren G, Su J, Zhao X, Zhang L, Zhang J, Roberts AI, et al. Apoptotic cells induce immunosuppression through dendritic cells: critical roles of IFN- $\gamma$ and nitric oxide. J Immunol (2008) 181:3277-84. doi:10.4049/jimmunol.181.5.3277

138. Perruche S, Zhang P, Liu Y, Saas P, Bluestone JA, Chen W. CD3-specific antibody-induced immune tolerance involves transforming growth factor-beta from phagocytes digesting apoptotic T cells. Nat Med (2008) 14:528-35. doi:10.1038/nm 1749

139. Bonnefoy F, Perruche S, Couturier M, Sedrati A, Sun Y, Tiberghien P, et al. Plasmacytoid dendritic cells play a major role in apoptotic leukocyteinduced immune modulation. J Immunol (2011) 186:5696-705. doi:10.4049/ jimmunol.1001523

140. Saas P, Daguindau E, Perruche S. Concise review: apoptotic cell-based therapies-rationale, preclinical results and future clinical developments. Stem Cells (2016) 34:1464-73. doi:10.1002/stem.2361

141. Saas P, Kaminski S, Perruche S. Prospects of apoptotic cell-based therapies for transplantation and inflammatory diseases. Immunotherapy (2013) 5:1055-73. doi:10.2217/imt.13.103

142. Elliott MR, Ravichandran KS. Clearance of apoptotic cells: implications in health and disease. J Cell Biol (2010) 189:1059-70. doi:10.1083/jcb.201004096

143. Muñoz LE, Lauber K, Schiller M, Manfredi AA, Herrmann M. The role of defective clearance of apoptotic cells in systemic autoimmunity. Nat Rev Rheumatol (2010) 6:280-9. doi:10.1038/nrrheum.2010.46

144. Lima LG, Chammas R, Monteiro RQ, Moreira ME, Barcinski MA. Tumorderived microvesicles modulate the establishment of metastatic melanoma in a phosphatidylserine-dependent manner. Cancer Lett (2009) 283:168-75. doi:10.1016/j.canlet.2009.03.041

145. Munoz LE, Franz S, Pausch F, Furnrohr B, Sheriff A, Vogt B, et al. The influence on the immunomodulatory effects of dying and dead cells of Annexin V. J Leukoc Biol (2007) 81:6-14. doi:10.1189/jlb.0306166

146. Gaipl US, Multhoff G, Scheithauer H, Lauber K, Hehlgans S, Frey B, et al. Kill and spread the word: stimulation of antitumor immune responses in the context of radiotherapy. Immunotherapy (2014) 6:597-610. doi:10.2217/ imt.14.38

147. Grag DA, Galuzzi L, Apetoh L, Baert T, Birge RB, Bravo-San Pedro SP, et al. Molecular and translational classifications of DAMPs in immunogenic cell death. Front Immunol (2015) 6:588. doi:10.3389/fimmu.2015.00588

Conflict of Interest Statement: The authors declare that the research was conducted in the absence of any commercial or financial relationships that could be construed as a potential conflict of interest.

Copyright (c) 2017 Szondy, Sarang, Kiss, Garabuczi and Köröskényi. This is an open-access article distributed under the terms of the Creative Commons Attribution License (CC BY). The use, distribution or reproduction in other forums is permitted, provided the original author(s) or licensor are credited and that the original publication in this journal is cited, in accordance with accepted academic practice. No use, distribution or reproduction is permitted which does not comply with these terms. 